\title{
Lorry drivers' work stress evaluated by catecholamines excreted in urine
}

\author{
Allard J van der Beek, Theo F Meijman, Monique H W Frings-Dresen, Judith I Kuiper, \\ Sijmen Kuiper
}

\begin{abstract}
Objectives-To evaluate lorry drivers' work stress by measurement of adrenaline and noradrenaline excreted in the urine, and to find out which factors in their working situation are related to the excretion rates of these catecholamines. Methods-The urinary excretion of adrenaline and noradrenaline of 32 lorry drivers, who also had loading and unloading activities to perform, was studied for one working day and one rest day. Each driver was asked to provide six urine samples on both days.

Results-For all samples, except the first (overnight) sample, the excretion rates of both catecholamines on the working day were higher than those on the rest day. Hierarchical multiple regression analyses were carried out to find out which factors in the drivers' working situation were related to the excretion rate of the working day. The excretion rate of adrenaline on the rest day, age, and psychosomatic complaints were positively related to the excretion rate on the working day (all $\mathbf{P}<$ 0.05). Body mass index and physical workload during loading and unloading were positively related to noradrenaline excretion rate (both $P<0.01$ ). Psychosocial job strain did not significantly contribute to the proportion of variance explained in the excretion rates of both catecholamines.
\end{abstract}

Conclusions-The excretion rates of adrenaline and, especially, noradrenaline on the working day were higher than those found in earlier studies among professional drivers and insufficient recovery took place after the work was ended. The only association between excretion rate on the working day and work stressors was found for noradrenaline and physical workload. The drivers' sympathoadrenal medullary reactivity to everyday work demands shows the characteristics of sustained activation.

(Occup Environ Med 1995;52:464-469)

Keywords: work stress; lorry drivers; catecholamines

Epidemiological studies have shown that working as a professional driver is associated with a high prevalence of musculoskeletal complaints, ${ }^{1-3}$ but cardiovascular disease is also common. ${ }^{4}$ Work demands associated with driving and its required alertness can be identified, ${ }^{5}$ but as well as these, psychophysiological arousal is affected as a result of physically demanding activities while loading and unloading.

The general function of the psychophysiological activation response (and its concomitant increase in secretion of catecholamines) is the improvement of coping successfully with a stressful situation. This is in principle an adaptive response. Pathological consequences may arise, however, in association with a prolonged increase in the concentrations of catecholamines. This so called sustained activation is found to be related to, for instance, cardiovascular disease. ${ }^{6-7}$ Catecholamine excretion rates, as assessed from urinary output of free adrenaline and noradrenaline, provide a reliable measure of the circulating concentrations of these hormones in the bloodstream and thus a measure of sympathoadrenal medullary activity. ${ }^{8}$ The excretion rate of adrenaline is closely related to each person's appraisal of the situation and the resulting emotional involvement. ${ }^{9}$ Among others Dimsdale and Moss provided evidence for the hypothesis that physical effort is a main determinant of high noradrenaline excretion rates, ${ }^{10}$ although the effect of severe emotional stress is probably also important.

Extensive field studies of Mackie and Miller among lorry and bus drivers showed that circadian rhythmicity had the most important influence on the urinary excretion of catecholamines. ${ }^{11}$ In general, low excretion rates of both catecholamines were related to increased feelings of fatigue and poorer performance on several variables of steering and lane tracking. Participation in handling moderately heavy cargo showed an unclear picture-that is, in one group of lorry drivers loading and unloading were associated with higher noradrenaline excretion rates and, surprisingly, in another group with lower noradrenaline excretion rates. Excretion rates of adrenaline and noradrenaline on the working day in one occupational group of professional drivers (bus, heavy goods vehicle, heavy plant) were similar to the population mean of a large sample of workers in a wide variety of occupations. ${ }^{12}$ Among city bus drivers with high sickness frequency mean excretion rate on the working day was higher than the population mean (already mentioned) for adrenaline, but not for noradrenaline. This was repeatedly shown in three interrelated studies. ${ }^{13-15}$ Recently, Vivoli et al reported that three long distance lorry drivers showed their 
highest urinary excretion rates for both catecholamines in stressful driving conditions, such as fog or traffic jams. ${ }^{16}$ The question remains unsolved, however, to what extent the excretion of adrenaline and noradrenaline is affected by performing physical work as well as driving. Therefore, lorry drivers who also had loading and unloading activities to perform were studied to gain an insight into the effect of combined exposure to physical and mental work demands. The aim of this study was twofold: to evaluate lorry drivers' work stress by means of urinary excreted adrenaline and noradrenaline, and to find out which factors in their working situation are related to the excretion rate of adrenaline and noradrenaline. The null hypotheses that were tested were (a) that there were no differences in excretion rate of the catecholamines between the working and rest days, and $(b)$ that physical workload and psychosocial job strain were not related to catecholamine excretion rate on the working day when controlled for excretion rate on the rest day, body mass index, age, and psychosomatic complaints.

\section{Subjects and methods}

\section{SUBJECTS}

The study population consisted of 32 male lorry drivers engaged in transportation of goods throughout The Netherlands. The subjects originated from three different companies and were randomly selected from all lorry drivers in their company. Each driver who was asked to participate voluntarily agreed to do so. The mean (SD, range) age of these drivers was $38 \cdot 2(8 \cdot 0,26$ to 54$)$ years. Their weight was $84.5(13.7,50$ to 111$) \mathrm{kg}$, and their height was $1.79(0.05,1.70$ to 1.90$) \mathrm{m}$. The body mass index was $26 \cdot 3(4 \cdot 2,17 \cdot 3$ to $33 \cdot 6)$ $\mathrm{kg} \mathrm{m}^{-2}$.

The drivers worked on average more than $11 \mathrm{~h} \mathrm{day}{ }^{-1}$. Driving was the main task with almost half of the total working time spent behind the wheel. Loading and unloading (including preparation for this and completion) were performed for a quarter of the total working time. ${ }^{17}$ Due to large differences in goods and the way these goods were transported (on wheeled cages, as packed goods, on palettes, or as bulk cargo) corresponding loading and unloading activities varied. For some drivers these activities consisted mainly of heavy pushing and pulling, whereas other drivers more often lifted and carried goods manually. The loading and unloading of bulk cargo was done mechanically. Furthermore, psychosocial aspects of the work differed considerably between drivers. For instance, several drivers worked with deadlines and under serious time pressure while distributing miscellaneous goods throughout The Netherlands, and others experienced hardly any time pressure while collecting milk from farmers and transporting it to a dairy factory. Additional differences in psychosocial strain were caused by long waiting times before loading and unloading, which was reported to be stressful by most drivers. All drivers worked alone, on a fixed salary, and no one had to handle hazardous materials.

\section{MEASUREMENTS AND QUESTIONNAIRE}

Urine collection and analysis

Each driver was studied during a working day and asked to provide six urine samples on that day: (1) after getting up (0700), (2) in the morning (1000), (3) at lunch time (1400), (4) at the end of working time $(1730),(5)$ in the evening (2000), and (6) before going to bed (2300). They were asked to do the same on the next Sunday (rest day). The drivers recorded times of all urinations, including the last urination of the night before. Data on consumption of coffee, tea, alcohol, and medicine during both days were collected. On Monday each driver verified his previous statement that no physical work-for example, sports activities or house rebuilding-was performed on his preceding rest day. Furthermore, it was asked whether emotional events, like a quarrel or otherwise traumatic incidents, had occurred. One driver's father was taken into hospital with symptoms of a heart attack on Sunday. This subject collected his urine again on the next Sunday.

The drivers were asked to urinate in a jar that contained $0.7 \mathrm{~g}$ of citric acid. After assessment of the volume of the urine sample, $20 \mathrm{ml}$ from each sample was acidified with $0 \cdot 1$ $\mathrm{ml} 10 \mathrm{M} \mathrm{HCl}$ and kept frozen $\left(-20^{\circ} \mathrm{C}\right)$ until analysis. The urinary catecholamine concentrations were determined by high performance liquid chromatography with fluorescence detection by the method of Boos et al. ${ }^{18}$

\section{Physical workload}

The heart rate was continuously recorded during the working day and related to observed tasks, including loading and unloading. The individual linear relation between heart rate and oxygen uptake during a simulation of loading and unloading and the maximal oxygen uptake $\left(\dot{V}_{\mathrm{O}_{2 \max }}\right)$ were measured in a laboratory treadmill test for each driver. Details of this test and the procedure in the laboratory are given elsewhere. ${ }^{17}$ Thus, with the individual relation and the heart rate recorded at work, the mean percentage of $\dot{V}_{\mathrm{O}_{2 \max }}$ during loading and unloading in the working situation could be calculated for each driver as an indicator of physical workload. It seemed that the mean (SD, range) of $\dot{V}_{\mathrm{O}_{2 \max }}$ during loading and unloading was $39 \%(14 \%$, $14 \%$ to $66 \%$ ).

\section{Psychosomatic complaints and psychosocial job} strain

Each driver completed a questionnaire that has been described previously. ${ }^{3}$ Most of the questions that were relevant for the present study were adopted from other, existing, questionnaires. A general health questionnaire was included"; this so called "VOEG" measures somatised psychosocial problems. ${ }^{20}$ It provides 21 dichotomous questions on complaints about general fatigue, the stomach, and the musculoskeletal and cardiovascular systems. The mean ( $\mathrm{SD}$, range) score on the 
Figure 1 Mean $(S D)$ of the urinary excretion rate and six samples at comparable hours on the rest day. of adrenaline for six samples on the working day

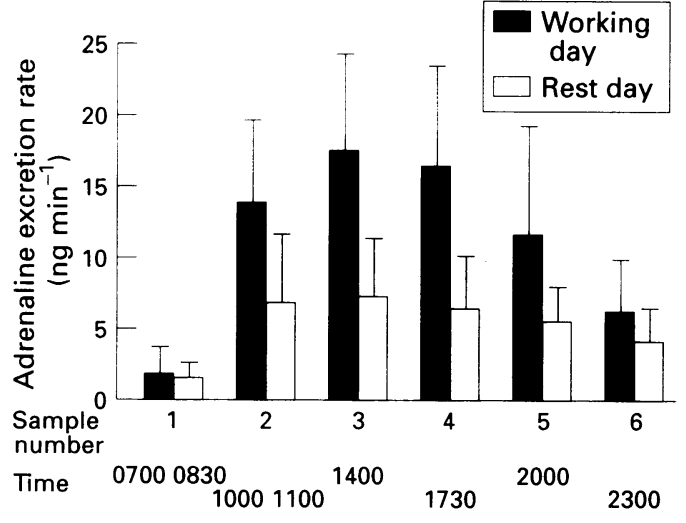

VOEG scale was $4 \cdot 3(3 \cdot 8,0$ to 13$)$; a higher score indicates more psychosomatic complaints. The VOEG is widely used in The Netherlands (for instance in the Dutch continuous health interview survey), and its reliability and validity has been studied extensively. ${ }^{21}$

The variable psychosocial job strain was measured by means of a Dutch version of the job demands and decision latitude questionnaire. ${ }^{22-23}$ The $z$ scores of the scale "autonomy" (five questions) were added to those of the scale "task variety" (three questions) and divided by 2 , which resulted in decision latitude scores. The variable psychosocial job strain was computed by subtracting these decision latitude scores from the $z$ scores of the scale "psychological job demands" (eight questions). The variable psychosocial job strain averaged, of course, $0 \cdot 0$ (SD $1 \cdot 7$, range $-3 \cdot 1$ to $3 \cdot 3$ )

\section{DATA ANALYSIS AND STATISTICS}

The urinary catecholamine concentrations were multiplied by the volume of the corresponding urine sample. This amount was divided by the period of time between the urination of this sample and the previous urination to obtain the mean excretion rate for that period (ng min ${ }^{1}$ ). For each day a repeated measures analysis of variance (MANOVA; $F$ test) was performed to test whether there were diurnal differences. If so, differences between the working day and rest day were tested.

To evaluate the hormonal reaction during work and thereafter, samples 3 to 6 (the

Figure 2 Mean (SD) of the urinary excretion rate of noradrenaline for six samples on the working day and six samples at comparable hours on the comparable
rest day.

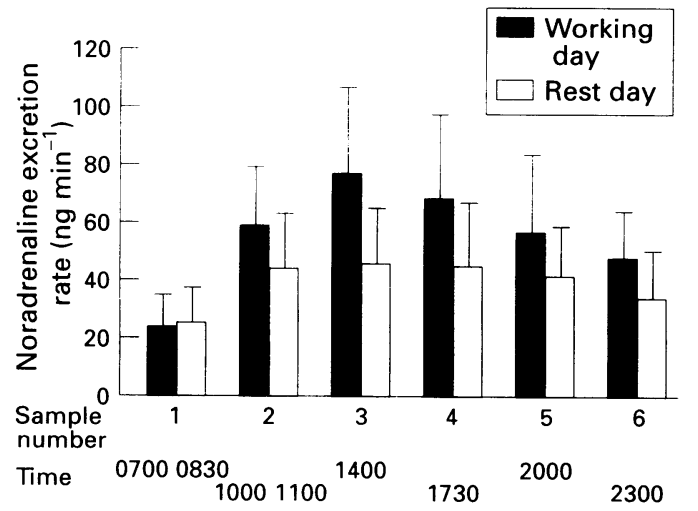

period from around 1000 until the end of the day) were analysed. Samples 1 and 2 were unsuitable for this purpose, because the first sample was from the overnight period and the second sample included around an hour and a half of daily activities at home and commuting between home and the transport company. The mean urinary excretion rates for the period from around 1000 until the end of the day were calculated for adrenaline and noradrenaline, both for the working day and the rest day. With these data hierarchical multiple regression analyses were carried out for both catecholamines. The catecholamine excretion rate on the working day was the dependent variable. The excretion rate on the rest day, body mass index, and age were entered into the first step as independent variables. The variable psychosomatic complaints was entered into the second step. Into the third step two variables about the working situation were introduced: percentage of $\dot{V}_{\mathrm{O}_{2} \text { ax }}$ during loading and unloading as an indicator of physical workload and psychosocial job strain.

In all analyses differences were accepted as significant at $\mathrm{P}<0.05$; if so, we have stated whether the level was $\mathrm{P}<0.05, \mathrm{P}<0.01$, or $\mathrm{P}<0.001$.

\section{Results}

For the different samples on the working and rest days the urine samples of around 30 drivers were collected, with the exception of sample 2 on the rest day (only 20 urine samples were collected for this period). Most of the missing samples were because drivers were not able to urinate at the requested time. Consumption of coffee, tea, alcohol, and medicine did not differ between the working and rest days.

Figure 1 shows the mean (SD) of urinary excretion rates of adrenaline on the working and rest days. The urination times of samples 1 and 2 on the rest day seemed to be later than those on the corresponding working day, because the drivers slept somewhat longer on the rest day. On both days a circadian rhythmicity is notable (MANOVA: $\mathrm{P}<0.001$ for both days). The peak concentration was reached around midday (sample 3; 17.5 and $7 \cdot 3 \mathrm{ng} \mathrm{min}{ }^{1}$ ) on the working and rest day respectively. The first (overnight) sample showed no difference in excretion rate between the working and rest days. For the period from 0700 to 1730 (samples 2, 3, and 4 ) the excretion rates of adrenaline on the working day were significantly higher than those on the rest day $(P<0.001)$. Although work ended around 1730, the last two samples on the working day (11.6 and $6.2 \mathrm{ng}$ $\min ^{-1}$ ) were significantly higher than those of the rest day $\left(5.6\right.$ and $\left.4.1 \mathrm{ng} \min ^{-1}\right), \mathrm{P}<$ 0.001 and $P<0.01$, respectively.

The mean urinary excretion rate of noradrenaline ranged from 23.9 to $77.0 \mathrm{ng} \mathrm{min}{ }^{-1}$ on the working day and from 25.3 to $45.9 \mathrm{ng}$ $\min ^{-1}$ on the rest day (fig 2 ). Diurnal differences in noradrenaline excretion rate were significant (MANOVA: $\mathrm{P}<0.001$ for both 
Table 1 Stepwise multiple regression with adrenaline excretion rate on the working day as the dependent variable $(n=29)$

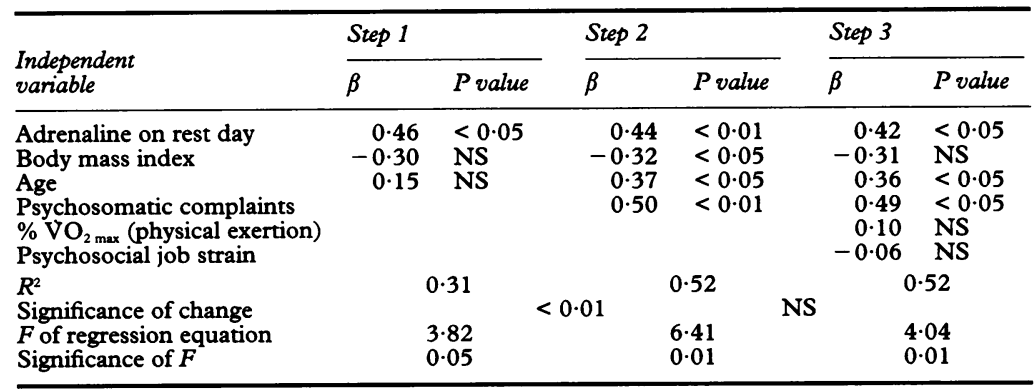

days). Again, differences in excretion rate between the working day and the rest day were significant for samples 2,3 , and $4(P<$ 0.001 ), but not for sample 1 . When the work was ended the noradrenaline excretion rate decreased, but did not return to the concentration of the corresponding samples on the rest day (sample 5: $P<0.05$, and sample 6: $P$ $<0.01)$.

Table 1 shows the results of hierarchical multiple regression analyses for the urinary excretion rate of adrenaline on the working day. A significant increase in $R^{2}$ occurred by the second step, when the variable psychosomatic complaints was entered into the regression model (from 0.31 to $0.52, \mathrm{P}<0.01$ ). The introduction in step 3 of the two variables about the working situation (percentage of $\dot{V} \mathrm{O}_{2 \max }$ during loading and unloading and psychosocial job strain) had no further effect. The regression equation that contained all five of the independent variables was significant $(P<0.01)$; the proportion of variance explained in adrenaline excretion rate on the working day was $52 \%$. The effects on adrenaline excretion rate of the rest day, age, and psychosomatic complaints were significant (all $\mathrm{P}<0.05$ ).

The same multiple regression procedures were performed for the urinary excretion rate of noradrenaline on the working day (table 2). For this variable the entrance of the variable psychosomatic complaints into the regression model (step 2) was not significant. A significant change of $R^{2}$ occurred when the variables about the working situation were added in the third step. The proportion of variance explained increased from $47 \%$ to $64 \%$ ( $P<$ $0.05)$. This increase was due to the impact of the percentage of $\dot{V}_{\mathrm{O}_{2 m a x}}$ during loading and unloading. When all five of the independent

Table 2 Stepwise multiple regression with noradrenaline excretion rate on the working day as the dependent variable $(n=29)$

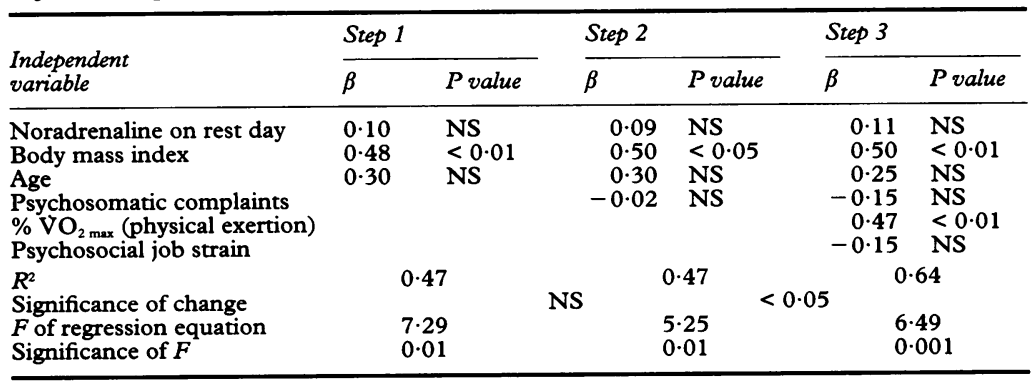

variables were included in the regression equation $(P<0.001)$, body mass index, and percentage of $\dot{V}_{\mathrm{O}_{\max }}$ provided a significant contribution to variance explained in the excretion rate of the working day (both $\mathrm{P}<$ $0 \cdot 01)$.

\section{Discussion}

Catecholamines excreted in the urine were studied in 32 lorry drivers who performed physical work as well as driving. In general, excretion rates of adrenaline and noradrenaline on the rest day were comparable with those found in previous studies. ${ }^{12}$ On the working day the absolute mean excretion rates of adrenaline were somewhat higher than those found before in professional drivers, ${ }^{11-13}$ and were similar to the rates that were found in stressful driving conditions. ${ }^{16}$ The excretion rates of noradrenaline on the working day considerably exceeded those found in earlier studies among professional drivers. ${ }^{11-12}$ As most of the time the handling of materials during loading and unloading was done by the lorry drivers without assistance, this finding was consistent with the theory that noradrenaline reflects physical exertion. ${ }^{10}$ The study by Vivoli et $a l^{16}$ has shown that emotional stress can also provoke noradrenaline excretion. ${ }^{16}$ Two of three long distance lorry drivers, who performed no physical work in addition to driving, showed very high urinary excretion rates for noradrenaline due to severe stress while driving in fog. In summary, it is considered that there are indications that the work stress of the lorry drivers in the present study was rather high, which was confirmed by the finding that at the end of the working day insufficient recovery took place.

Almost one third of the variance in urinary excretion rate of adrenaline on the working day was explained by the excretion rate on the rest day, body mass index, and age. For noradrenaline almost half of the variance was explained by these variables. Body mass index was negatively correlated with adrenaline excretion rate and positively correlated to noradrenaline excretion rate, which is in accordance with data that have been reviewed by Landsberg. ${ }^{24}$ When psychosomatic complaints, percentage of $\dot{V}_{\mathrm{O}_{2 \max }}$, and psychosocial job strain were added to the regression model the proportion of variance explained increased by around $20 \%$. For adrenaline the variable psychosomatic complaints accounted for most of this increase, and for noradrenaline the variable percentage of $\dot{V O}_{2 \max }$ was most important. The results of adrenaline correspond to the findings of Meijman et al, ${ }^{25}$ who found that the differential reactivity of adrenaline, but not noradrenaline, was related to psychosomatic complaints, and the noradrenaline results indicate that noradrenaline excretion reflects physical exertion.

To find out which factors in the working situation of lorry drivers were related to a high catecholamine excretion rate, two variables of the working situation were introduced into the third multiple regression step-that is, 
percentage of $\dot{V}_{\mathrm{O}_{2}}$ max during loading and unloading as an indicator of physical workload and psychosocial job strain. The finding that the variable percentage of $\dot{V O}_{2 \text { max }}$ was significantly related to the excretion rate of noradrenaline but not adrenaline was in agreement with the theory already discussed. Psychosocial job strain did not provide a significant contribution to the proportion of variance explained in excretion rate of both catecholamines on the working day. According to Karasek and Theorell stressful psychosocial work factors are associated with negative health effects. ${ }^{23}$ In the present study psychosocial job strain was indeed positively related to psychosomatic complaints. As the variable psychosomatic complaints was included in the model earlier (step 2), the impact of the addition of the variable psychosocial job strain on the excretion rate of adrenaline on the working day could be diminished. Even when the variable psychosomatic complaints was not included at all in the regression model, self reported psychosocial job strain was not significantly associated with adrenaline excretion rate on the working day. Johansson et al found that a group of workers with a psychologically demanding job (in the opinion of experts as well as the workers themselves) showed higher excretion of adrenaline when compared with a control group. ${ }^{26}$ Schaubroeck and Ganster used expert ratings to assess occupational mental demands and found that this variable was negatively related to adrenaline concentration in urine at midday when at work. ${ }^{27}$ It is considered that future studies should clarify these conflicting results. The use of objective measures of psychosocial job strain is recommended in these studies, because subjective evaluations (whether by experts or by workers) might cause serious bias.

High catecholamine excretion rates can be interpreted in two different ways, which are contradictory to each other with respect to the relation with health. The theory of "sustained activation" predicts that prolonged high excretion rates due to exposure to stressors are associated with negative health effects. ${ }^{6-7}$ On the other hand, Dienstbier stated that the concept of physiological toughness, which is associated with psychosomatic wellbeing and better performance, is applicable to human sympathoadrenal medullary reactivity to stressors. ${ }^{28-29}$ In short, tough and healthy people have low baseline rates, and their positive appraisals lead to high reactivity to stressors and good performance, after which they return relatively quickly to baseline rates. It is possible to change this physiological process by means of exposure to certain stressors. These so called toughening manipulations can lead to an increased toughness. In other words, "stress may be adaptive and result in training rather than straining". ${ }^{30}$ Exposure to stressors should be intermittent - that is, sufficient recovery periods should be included in the toughening programme. ${ }^{29}$ An important statement on the toughness concept can be made. According to Dienstbier in most stud- ies in which performance was related to physiological activation either novel tasks in laboratory settings or vitally important tasks (such as parachute training) were used..$^{29}$ Thus, the question arises whether the relation between toughness and psychosomatic wellbeing and endocrine reactions still holds when endocrine measures are obtained during everyday stressful working situations. ${ }^{31}$ The present study showed that (over and above the excretion rate on the rest day) psychosomatic complaints provided a significant contribution to the proportion of variance in adrenaline excretion rate on the working day. Moreover, when the samples were analysed separately, it seemed that during work (samples 3 and 4) as well as thereafter (samples 5 and 6) the reactivity of adrenaline was related to the self reported health of the subject in the same direction-that is, the more psychosomatic complaints the higher the adrenaline excretion rates. On the other hand, the excretion rates of adrenaline on the rest day did not show any relation with psychosomatic complaints. Both findings are in conflict with the expectations obtained from the toughness model. This indicates that stressors during daily work of lorry drivers cannot be interpreted as recurring challenges that may lead to increased toughness of the drivers. On the contrary, when incapacity to eliminate the source of stress is not accompanied by habituation, the stressful working situation leads to a chronic increased sympathoadrenal reactivity to the normal daily work routine-that is, sustained activation. This constantly high level of physiological activation is associated with somatic pathology and psychosomatic complaints, ${ }^{6-7}$ which was confirmed in this study.

\section{CONCLUSIONS}

The working day excretion rates of adrenaline and, especially, noradrenaline were higher than those found in earlier studies among professional drivers. Moreover, insufficient recovery took place after the work was ended. Excretion rate of adrenaline on the working day was related to psychosomatic complaints but not to psychosocial job strain. For excretion rate of noradrenaline the physical workload during loading and unloading was an important explanatory variable. It is considered that lorry drivers' sympathoadrenal medullary reactivity to everyday work demands shows the characteristics of sustained activation, and that the concept of toughness is not applicable to their real working situation.

We thank Jake PJ Broersen for his valuable advice on the multiple regression analyses.

\footnotetext{
Backman A-L. Health survey of professional drivers. Scand f Work Environ Health 1983;9:30-5.

Hedberg GE. The period prevalence of musculoskeletal complaints among Swedish professional drivers. Scand $\mathscr{f}$ Soc Med 1988;16:5-13.

3 Van der Beek AJ, Frings-Dresen MHW, Van Dijk FJH, Kemper HCG, Meijman TF. Loading and unloading by lorry drivers and musculoskeletal unloading by International fournal of Industrial Ergonomics 1993;12: 13-23.

4 Belkić K, Savić Ć, Theorell T, Rakić L, Ercegovac D,
} 
Diordjević $M$. Mechanisms of cardiac risk among professional drivers. Scand 7 Work Environ Health 1994 20:73-86.

5 McDonald N. Fatigue, safety, and the truck driver. London: Taylor and Francis, 1984.

6 Ursin H. Personality, activation and somatic health: a new psychosomatic theory. In: Levine $\mathrm{S}$, Ursin $\mathrm{H}$, eds Coping and health. New York: Plenum Press, 1980:259-79.

7 Knardahl S, Ursin H. Sustained activation and the pathophysiology of hypertension and coronary heart disease. Psychophysiology of cardiovascular control. Models, methods and data. New York: Plenum Press, 1985:223-37.

8 Moleman P, Tulen JHM, Blankestijn PJ, Man in 't Veld AJ, Boomsma F. Urinary excretion of catecholamines AJ, Boomsma F. Urinary excretion of catecholamines and their metabolites in relation to circulating

9 Frankenhaeuser M. Psychoneuroendocrine approaches to the study of emotion as related to stress and coping. In Howe HE, Dienstbier RA, eds. Nebraska Symposium on Motivation 1978. Lincoln: University of Nebraska Press, 1979:123-61

10 Dimsdale JE, Moss J. Plasma catecholamines in stress and exercise. $\mathcal{F} A M A$ 1980;243:340-3.

11 Mackie RR, Miller JC. Effects of hours of service, regularity of schedules and cargo loading on truck and bus driver fatigue. Goleta, California: Huma

12 Jenner DA, Reynolds V, Harrison GA. Catecholamine excretion rates and occupation. Ergonomics 1980;23: 237-46.

13 Mulders HPG, Meijman TF, O'Hanlon JF, Mulder G. Differential psychophysiological reactivity of city bus drivers. Ergonomics 1982;25:1003-11.

14 Kompier MAJ, Mulders HPG, Broersen JPJ, Westerink B Meijman TF. Psychosomatic complaints and absence behaviour as indicators of future breakdown in adaptation. In: Oborne DJ, ed. Contemporary ergonomics 1986. London: Taylor and Francis, 1986:232-6.

15 Mulders HPG, Meijman TF, Kompier MAJ, Mulder G, Broersen JPJ, Westerink B, O'Hanlon JF. Occupational Broes in city bus drivers. In. Rothengather JA, De Bruin $\mathrm{RA}$, eds. Road user behaviour, theory and research. Assen: RA, eds. Road user behaviour,

16 Vivoli G, Bergomi M, Rovesti S, Carrozzi G, Vezzosi A Biochemical and haemodynamic indicator of stress in Biochemical and haemodynamic indicator

17 Van der Beek AJ, Frings-Dresen MHW. Physical workload of lorry drivers: a comparison of four methods of trans- port. Ergonomics 1995;38:(in press).

18 Boos K-S, Wilmers B, Sauerbrey $R$, Schlimme E Development and performance of an automated HPLCanalyzer for catecholamines. Chromatographia 1987;24: 363-70.

19 Dirken JM. Arbeid en Stress. Het vaststellen van aanpassingsproblemen in werksituaties (Work and stress. Assessment of adaptation problems in working situations). Groningen: $\mathrm{JB}$ Wolters, 1967. (English summary.)

20 Visser $\mathrm{APh}$. De betekenis van de VOEG: enkele gegeven over de begripsvaliditeit. (The meaning of the VOEG: some data on the construct validity). Gezondheid en Samenleving 1983;4:177-88.

21 Van Sonsbeek JLA. De gezondheidsmeting in de continue gezondheidsenquête van het CBS: aspecten van de betrouwbarheid en validiteit. The measurement of health in the Dutch contir health in the Dutch con in Stat Health Interview Survey of the Central Bureau of Statistics: aspects of the relia-

Karasek RA. Job demands, job decision latitude, and men-

Karasek RA. Job demands, job decision latitude, and mental strain: implications for job redes
Science Quarterly 1979;24:285-305.

23 Karasek RA, Theorell T. Healthy work: stress, productivity, and the reconstruction of working life. New York: Basis Books, 1990.

24 Landsberg L. Pathophysiology of obesity-related hypertension: role of insulin and the sympathetic nervous system. f Cardiovasc Pharmacol 1994;23(suppl 1):S1-S8.

25 Meijman TF, Mulders HPG, Kompier MAJ, Van Dormolen $M$. Individual differences in adrenaline/noradrenaline reactivity and self-perceived health status. $Z$ Grenaline reactivity and self-

26 Johansson G, Aronsson G, Lindström BO. Social psychological and neuroendocrine stress reactions in highly logical and neuroendocrine stress reactions

27 Schaubroeck J, Ganster DC. Chronic demands and Schaubroeck J, Ganster DC. Chronic demands and
responsivity to challenge. $\mathcal{F}$ Appl Psychol 1993;78:73-85.

28 Dienstbier RA. Arousal and physiological toughness: implications for mental and physical health. Psychol Rev 1989;96:84-100

29 Dienstbier RA. Behavioral correlates of sympathoadrenal reactivity: the toughness model. Med Sci Sports Exerc $1991 ; 23: 846-52$

30 Ursin $H$, Olff $M$. The stress response. In: Stanford C, Salmon P, Gray J, eds. Stress: an integrated approach. New York: Academic Press, 1992.

31 Meijman TF. Coping with work demands: some remarks on the role of catecholamines. In: Henschel $U$, ed. Experimental psychosomatics. Leiden: Leiden University Press, 1993:77-98.

\section{Correspondence and editorials}

Occupational and Environmental Medicine welcomes correspondence relating to any of the material appearing in the journal. Results from preliminary or small scale studies may also be published in the correspondence column if this seems appropriate. Letters should be not more than 500 words in length and contain a minimum of references. Tables and figures should be kept to an absolute minimum. Letters are accepted on the understanding that they may be subject to editorial revision and shortening.

The journal also publishes editorials which are normally specially commissioned. The Editor welcomes suggestions regarding suitable topics; those wishing to submit an editorial, however, should do so only after discussion with the Editor. 